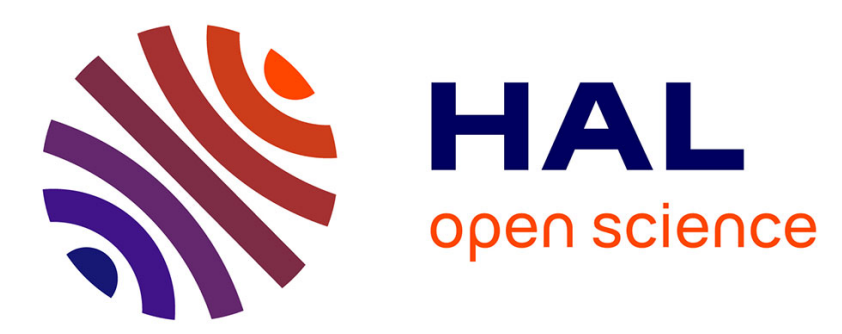

\title{
Feedback stabilization of discrete-time nonlinear systems via the Control Lyapunov functions
}

\author{
Abderrahman Iggidr, Mohamed Oumoun, Jean-Claude Vivalda
}

\section{To cite this version:}

Abderrahman Iggidr, Mohamed Oumoun, Jean-Claude Vivalda. Feedback stabilization of discretetime nonlinear systems via the Control Lyapunov functions. 38th IEEE Conference on Decision and Control, Dec 1999, Phoenix, Arizona, United States. pp.2051-2052. hal-01862872

HAL Id: hal-01862872

https://hal.inria.fr/hal-01862872

Submitted on 29 Aug 2018

HAL is a multi-disciplinary open access archive for the deposit and dissemination of scientific research documents, whether they are published or not. The documents may come from teaching and research institutions in France or abroad, or from public or private research centers.
L'archive ouverte pluridisciplinaire HAL, est destinée au dépôt et à la diffusion de documents scientifiques de niveau recherche, publiés ou non, émanant des établissements d'enseignement et de recherche français ou étrangers, des laboratoires publics ou privés. 


\title{
Feedback stabilization of discrete-time nonlinear systems via the Control Lyapunov Functions
}

\author{
A. Iggidr M. Oumoun J.C. Vivalda \\ Inria-lorraine (CONGE Project) \& UPRESA-CNRS 7035 \\ Université de Metz - ISGMP Bat. A - Ile du Saulcy \\ 57045 Metz cedex 01 - FRANCE. \\ e-mail: \{iggidr, oumoun, vivalda\}@loria.fr
}

\begin{abstract}
In this paper we state sufficient conditions for the existence of feedback laws which render the equilibrium solution of a class of discrete-time nonlinear systems globally asymptotically stable.
\end{abstract}

Keywords: Control Lyapunov Functions, Nonlinear discrete-time systems, Feedback stabilization.

\section{Introduction:}

Feedback stabilization of various classes of discretetime nonlinear systems have been studied in the past few years; see $([1,2,4,5])$ and references therein.

We consider the single-input discrete-time nonlinear systems of the form

$$
x_{k+1}=f\left(x_{k}\right)+u_{k} g\left(x_{k}\right), \quad x_{k} \in \mathbb{R}^{n}, \quad u \in \mathbb{R}
$$

where $f$ and $g$ are smooth on $\mathbb{R}^{n}$ and $f(0)=0$.

We say that (1) is globally asymptotically stable at the origin, if there exists a map $x \longmapsto K(x)$ such that the resulting system

$$
x_{k+1}=f\left(x_{k}\right)+K\left(x_{k}\right) g\left(x_{k}\right)
$$

is globally asymptotically stable at $0 \in \mathbb{R}^{n}$.

The main object of this paper is to provide explicit feedback $K: \mathbb{R}^{n} \longrightarrow \mathbb{R}$, smooth on $\mathbb{R}^{n} \backslash\{0\}$ and $K(0)=0$ such that $u_{k}=K\left(x_{k}\right)$ globally asymptotically stabilizes the origin of the system (1), under the assumption that a 'quadratic Control Lyapunov Function' is known. This problem has been addressed for stochastic systems in [3].

This result represents a continuation of a line of work started in [7], in which, under the same condition, the author has studied the local stabilization for the multiinputs discrete-time systems affine in the control, and the practical stabilization for the single-input systems.

\section{Stabilization and clf's}

In this section, we will state and prove an analogous of Sontag's result [6] for discete-time systems.

Definition 1 A smooth, proper and definite positive function $V$ mapping $\mathbb{R}^{n}$ into $\mathbb{R}$ is said to be a control Lyapunov function (henceforth just 'clf') for the discrete systems (1) if and only if,

$$
\inf _{u_{k} \in \mathbb{R}}\left(\Delta V\left(x_{k}, u_{k}\right)=V\left(x_{k+1}\right)-V\left(x_{k}\right)\right)<0, \quad \forall x \in \mathbb{R}^{n} \backslash\{0\}
$$

In the following, we will assume that $V$ is a quadratic clf for system (1) (i.e. there exists a positive definite matrix $P$ such that $V(x)=x^{T} P x=\|x\|_{p}^{2}=\langle x, x\rangle_{p}$

Remark: In [1], the authors have studied the same problem and have given, under the same assumptions, the following feedback

$u(x)= \begin{cases}0 & \text { for } x \in \Omega_{0}=\left\{\in \mathbb{R}^{n}: g(x)=0\right\} \\ -\frac{\langle f(x), g(x)\rangle_{p}}{\|g(x)\|_{p}^{2}} & \text { for } x \in \Omega_{1}=\left\{x \in \mathbb{R}^{n}: g(x) \neq 0\right\}\end{cases}$

but it is easy to show that $\lim _{x \in \Omega_{1} \rightarrow x_{0}} u(x)=\infty$ for all $x_{0} \in \partial \Omega_{0} \backslash\{0\}$ such that $f\left(x_{0}\right) \neq 0$ and so $u(x)$ is not only discontinuous but is also unbounded in a neighbourhood of such a point.

Here, we will construct a stabilizing feedback which is smooth on $\mathbb{R}^{n} \backslash\{0\}$.

Theorem 1 If there is a quadratic 'clf' for the discrete-time system (1), then there is a stabilizing feedback $K: \mathbb{R}^{n} \longrightarrow \mathbb{R}$, smooth on $\mathbb{R}^{n} \backslash\{0\}$ and $K(0)=0$.

Proof: For every $(x, u) \in \mathbb{R}^{n} \times \mathbb{R}$, we let

$h_{x}(u)=u^{2}\|g(x)\|_{p}^{2}+2 u\langle f(x), g(x)\rangle_{p}+\|f(x)\|_{p}^{2}-\|x\|_{p}^{2}$

and we introduce the sets $\Omega_{0}=\left\{x \in \mathbb{R}^{n} \backslash\{0\} \mid g(x)=\right.$ $0\}$ and $\Omega_{1}=\left\{x \in \mathbb{R}^{n} \backslash\{0\} \mid g(x) \neq 0\right\}$. 
An easy computation shows that, for a given command law $u$, the difference $\Delta V=V\left(x_{k+1}\right)-V\left(x_{k}\right)$ is equal to $h_{x_{k}}\left(u_{k}\right)$. If $x \in \Omega_{0}$, this difference does not depend on $u\left(\Delta V=\left\|f\left(x_{k}\right)\right\|_{p}^{2}-\left\|x_{k}\right\|_{p}^{2}\right.$ in this case $)$ and is therefore negative since $V$ is a clf for system (1).

If $x \in \Omega_{1}$, for the same reason, the exists $u \in \mathbb{R}$ such that $h_{x}(u)<0$, this proves that $h_{x}(u)$ regarded as a polynomial in $u$ admits two separate roots $\lambda_{1}(x)$ and $\lambda_{2}(x)$. In this case our task is to find a function $K$ : $x \longmapsto K(x)$ such that $\lambda_{1}(x)<K(x)<\lambda_{2}(x)$ for all $x \in \Omega_{1}$.

First we take two smooth functions $\varphi$ and $\psi$ defined by:

$$
\varphi(t)=\left\{\begin{array}{ll}
0 & \text { if } t \leq 2, \\
1 & \text { if } t \geq 3
\end{array} \quad \psi(t)= \begin{cases}0 & \text { if } t \leq 0 \\
1 & \text { if } t \geq 1\end{cases}\right.
$$

and satisfying $0 \leq \varphi(t), \psi(t) \leq 1$ for all $t \in \mathbb{R}$.

Next, for $x \in \Omega_{1}$, we introduce the following quantities,

$$
\begin{aligned}
A(x)= & \left(\lambda_{1}(x)+1\right) \psi\left(\lambda_{1}(x)+1\right) \\
& +\left(\lambda_{2}(x)-1\right)\left(1-\psi\left(\lambda_{2}(x)-1\right)\right. \\
B(x)= & \varphi\left(\lambda_{2}(x)-\lambda_{1}(x)\right) \\
C(x)= & \frac{\lambda_{1}(x)+\lambda_{2}(x)}{2} .
\end{aligned}
$$

Finally, we claim that the following mapping $K$ defined by:

$$
K(x)= \begin{cases}0 & \text { if } x \in \Omega_{0} \\ A(x) B(x)+(1-B(x)) C(x) & \text { if } x \in \Omega_{1}\end{cases}
$$

is smooth on $\mathbb{R}^{n} \backslash\{0\}$ and globally asymptotically stabilizes system (1).

We first show that $K(x) \in] \lambda_{1}(x), \lambda_{2}(x)\left[\right.$ if $x \in \Omega_{1}$ :

- if $\lambda_{2}(x)-\lambda_{1}(x) \leq 2$, then $B(x)=0$ and so $K(x)=$ $C(x) \in] \lambda_{1}(x), \lambda_{2}(x)[$

- if $\lambda_{2}(x)-\lambda_{1}(x)>2$, by considering all the possible placements of $\lambda_{1}$ and $\lambda_{2}$ regarding 0 and 1 , we can see that $A(x) \in] \lambda_{1}(x), \lambda_{2}(x)$ [ which in turn implies that $K(x) \in] \lambda_{1}(x), \lambda_{2}(x)[$.

In order to show that $K$ is smooth on $\mathbb{R}^{n} \backslash\{0\}$, we remark first that this is obviously the case in the interior of $\Omega_{0}$ and in $\Omega_{1}$; we will next prove that if $x_{0} \in \partial \Omega_{0}$, there exists a neighborhood $U$ of $x_{0}$ on which $K$ vanishes.

Let $\varepsilon_{0}=-\left(\left\|f\left(x_{0}\right)\right\|_{p}^{2}-\left\|x_{0}\right\|_{p}^{2}\right), V$ is a clf implies $\varepsilon_{0}>0$. Let $\varepsilon>0$, since $g\left(x_{0}\right)=0\left(x_{0} \in \Omega_{0}\right)$, by continuity there exists a neighborhood $U$ of $x_{0}$ such that $\|f(x)\|_{p}^{2}-$ $\|x\|_{p}^{2}<-\varepsilon_{0} / 2,\|g(x)\|_{p}^{2}<\varepsilon$ and $2\left|\langle f(x), g(x)\rangle_{p}\right|<\varepsilon$. From these inequalities, we deduce that

$$
h_{x}(u) \leq \varepsilon u^{2}+\varepsilon|u|-\varepsilon_{0} / 2, \quad \forall(x, u) \in U \times \mathbb{R} .
$$

Now, in order to have $K(x)=0$ for all $x \in U \cap \Omega_{1}$, it is sufficient that $A(x)=0$ and $B(x)=1$ for all $x \in$ $U \cap \Omega_{1}$. To this end it is sufficient to have $\lambda_{1}(x) \leq-1$ and $\lambda_{2}(x) \geq 4$ which is equivalent to $h_{x}(-1) \leq 0$ and $h_{x}(4) \leq 0$; these last inequalities are satisfied in $U$ if $\varepsilon$ is chosen such that $\varepsilon \leq \varepsilon_{0} / 40$ and so the theorem is proven.

\section{References}

[1] G. L. Amicucci, S. Monaco and D. NormandCyrot, Control lyapunov stabilization of affine discretetime systems, Proc. 36th CDC, San Diego, CA, December 1997, 1 923-924.

[2] M. Bensoubaya, A. Ferfera and A. Iggidr. Stabilisation des systèmes non linéaires discrets, Comtes rendus de l'Academie des Sciences, Paris, Tome 321, Série I, No. 3, Août 1995, p. 371-374.

[3] R. Chabour and M. Oumoun, On a universal formula for the stabilization of control stochastic nonlinear systems, J. Stochastic Analysis and Applications, 17, No 3, 1999.

[4] A. Iggidr and M. Bensoubaya, New results on the stability of discrete-time systems and applications to control problems, J. of Math. Analysis and Applications 219 (1998), 392-414.

[5] D. Kazakos and J. Tsinias, The input to state stability and global stabilization of discrete-time systems, IEEE Tran. Aut. Cont. 39 (1994), 2111-2113.

[6] E. D. Sontag, A universal construction of Artstein's theorem on nonlinear stabilization, Systems \& control letters 13(1989),117-123.

[7] J. Tsinias, Stabilizability of discrete-time nonlinear systems, IMA J. Math. Cont. Inf 6 (1989), 135-150. 